\title{
S2 Fig:
}

Prevalence of validated disease phenotypes using EHR data among the total EHR population, all those tested for COVID-19, those who tested negative for COVID-19, COVID-19(+) individuals not needing admission and hospitalized for COVID-19(+) individuals. Numbers above bars are percentage for each group.

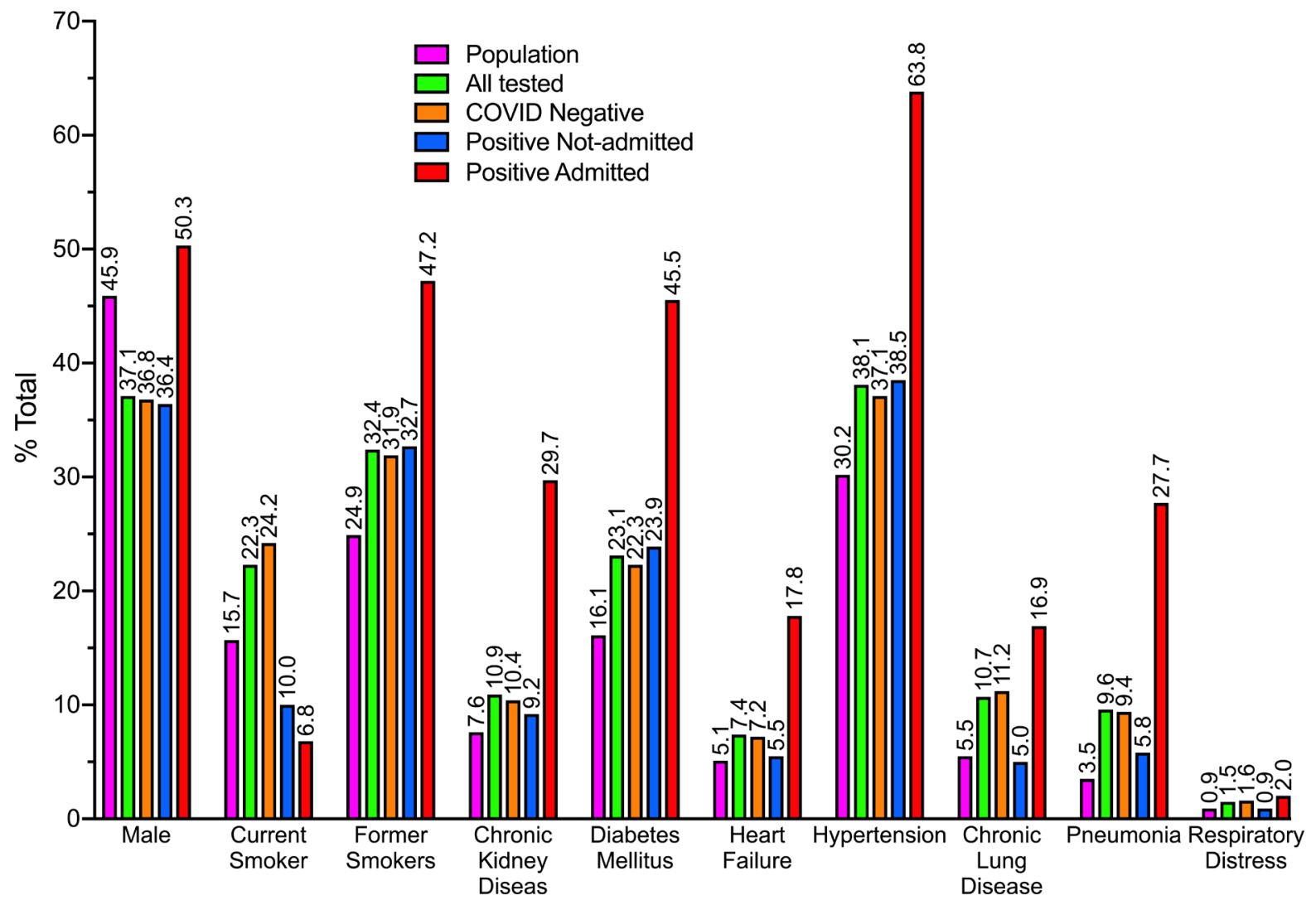

